\title{
Cidade Digital Estratégica: Modelo e Aplicação em um Município Paulista
}

\author{
Denis Alcides Rezende ${ }^{1}$ \\ ${ }^{1}$ Pontifícia Universidade Católica do Paraná (PUCPR) - Programa de Pós-Graduação \\ em Gestão Urbana - Rua Imaculada Conceição, 1155, Parque Tecnológico, Bloco 3 \\ Prado Velho - Curitiba - PR - Brasil. \\ denis.rezende@pucpr.br
}

\begin{abstract}
Smarts cities projects are planning and making information, systems and services available for their own managers and citizens. The aim of this paper is to describe the model for and the project called Strategic Digital City, implemented in the municipality of Vinhedo-SP. The research methodology was based on a case study formed by an action-research, considering the City Hall and local units. The results describe, through a specific methodology, the practical feasibility of the project and of the applied model. The conclusion reiterates the importance of a collective implementation of the model, and its acceptance as a tool to contribute to city management, to the fulfillment of the smart cities, to decision-making and to the citizens' quality of life.
\end{abstract}

Resumo. Projetos de Cidades Inteligentes planejam e disponibilizam informações, sistemas e serviços para seus gestores e cidadãos. O objetivo é descrever o modelo e o projeto Cidade Digital Estratégica realizado no município de Vinhedo-SP. A metodologia da pesquisa foi enfatizada por um estudo de caso que contemplou uma pesquisa-ação, considerando a Prefeitura $e$ unidades locais. Os resultados auferidos descrevem, por meio de uma metodologia, a viabilidade prática do modelo aplicado. A conclusão reitera a importância do modelo implantado coletivamente $e$ aceito como um instrumento para contribuir na gestão de municípios, na implementação de cidades inteligentes, nas decisões e na qualidade de vida dos munícipes.

\section{Introdução}

Projetos de Cidades Inteligentes planejam e disponibilizam informações, sistemas e serviços para seus gestores e cidadãos. $O$ planejamento de informações municipais requer a participação dos servidores municipais e dos cidadãos, sejam trabalhadores, estudantes, aposentados, donas de casa, vereadores, empresários entre outros.

O planejamento estratégico do município, o planejamento de informações municipais e o planejamento estratégico da tecnologia da informação são instrumentos de gestão das prefeituras e dos municípios de relevância inquestionável. Principalmente pelas dificuldades dos recursos financeiros nos municípios, pela obediência à Lei de Responsabilidade Fiscal, pela exigência do Estatuto da Cidade e pelas pressões dos munícipes e dos interessados na cidade (REZENDE; CASTOR, 2006). Essas pressões podem ser minimizadas pela elaboração e implementação desses planejamentos estratégicos participativos nos municípios, pois pode propiciar o envolvimento coletivo 
dos munícipes com seus anseios e também pode descentralizar e compartilhar as decisões dos gestores locais.

Destaca-se também como problema, a inexistência ou inadequação das informações municipais do meio ambiente interno e externo de algumas prefeituras corroborando com a dificuldade de gestão dos municípios e da respectiva participação dos cidadãos na gestão de cidades e respectivo desenvolvimento urbano e regional.

O objetivo é descrever o modelo e o projeto Cidade Digital Estratégica realizado no município de Vinhedo-SP. Tal projeto faz parte de um amplo projeto denominado Planejamento Estratégico da Tecnologia da Informação para Cidade Digital Estratégica. Contemplou a Prefeitura, suas Secretarias Municipais, uma Autarquia e demais unidades municipais, como escolas, postos de saúde, praças sociais de atendimento aos munícipes.

A justificativa para planejamento estratégico das informações municipais está principalmente relacionada com a estruturação, guarda e disponibilização dessas informações e o compartilhamento dos conhecimentos que não acontecem da noite para o dia e exigem projetos de planejamentos a curto, médio e longo prazo nas cidades.

\section{Fundamentação teórica}

\subsection{Planejamento de estratégias, de informações e da tecnologia da informação}

O Planejamento Estratégico do Município é um processo dinâmico, coletivo, participativo e interativo para determinação dos objetivos, estratégias, ações e controles do município, prefeitura e organizações públicas municipais. Tem como uma das bases os desafios, problemas e fraquezas do município, prefeitura e organizações municipais em questão, bem como, de outros municípios que de alguma forma influenciam ou se relacionam com o município a ser planejado (REZENDE; CASTOR, 2006).

O Planejamento de Informações Municipais é um projeto que formaliza as informações necessárias para a gestão da prefeitura e do município e como conseqüência planeja os sistemas de informações municipais e suas respectivas necessidades de recursos da tecnologia da informação e de recursos humanos (REZENDE, 2005).

O Planejamento Estratégico da Tecnologia da Informação é um processo dinâmico e interativo para estruturar estratégica, tática e operacionalmente as informações organizacionais, os sistemas de informação, a tecnologia da informação (e seus recursos: hardware, software, sistemas de telecomunicações, gestão de dados e informações), as pessoas envolvidas e a infra-estrutura necessária para o atendimento de todas as decisões, ações e respectivos processos da organização (TURBAN, McLEAN; WETHERBE, 1996; LEDERER; MAHANEY, 1996; REZENDE, 2011).

O alinhamento entre esses planejamentos municipais pode constituir-se a partir das satisfatórias relações verticais, horizontais, transversais, dinâmicas e sinérgicas das funções municipais e dos recursos da tecnologia da informação. $\mathrm{O}$ alinhamento pode promover o ajuste ou a adequação operacional e estratégica das tecnologias disponíveis de todo município, como uma ferramenta de gestão municipal contemplada pelos conceitos de qualidade, produtividade, efetividade, perenidade e inteligência municipal (HENDERSON; VENKATRAMAN, 1993; REZENDE; CASTOR, 2006). 


\subsection{Cidade digital, cidade inteligente e cidade digital estratégica}

O conceito de cidades inteligentes ou cidades digitais esta relacionado com a coleta e organização da informação digital de cidades para proporcionar um espaço de informação para que seus habitantes e visitantes interajam entre si (BESSELAAR; BECKERS, 2009). É o ambiente de rede digital criado no território, que interliga sistemas tecnológicos avançados para conectar serviços públicos, bens, marcas, escolas, organizações do terceiro setor, empresas, micro e macrocomunidades de pessoas, disponibilizando informações em diversas ordens e padrões com o propósito de desenvolver as potencialidades da sociedade de informações e transformar o cidadão em ator e protagonista de uma outra realidade: virtual (GUERREIRO, 2006).

As cidades se preocupam com as modificações físicas para proporcionar o funcionamento das cidades digitais com seus recursos tecnológicos e respectivos impactos conceituais, culturais e urbanos (ATKINSON, 1997; SHIODE, 2000). As cidades requerem novos elementos para sua organização e reprodução do espaço urbano, proporcionando o encolhimento das distâncias como cidades ampliadas, incluindo o uso das TICs (FIRMINO, 2004) ou como cidade em redes (BATTEN, 1995).

Para Lemos (2005) a ciência e a tecnologia tornam-se importantes para o desenvolvimento do espaço urbano. Os desafios do espaço urbano devem ultrapassar a barreira geográfica na virtualização das cidades ou no ciberespaço que pode proporcionar a possibilidade de anulação das distâncias entre os ocupantes de uma cidade, mesmo que seja a anulação da distância simbólica, pela comunicação sob forma digital (LEFEBVRE, 1991). As cidades transformam-se com o surgimento das novas tecnologias de comunicação como um movimento crescente de desterritorialização dos mundos simbólicos e esfacelamento de fronteiras entre o arcaico e o moderno, entre o local e o global, a cultura letrada e a audiovisual, possibilitando processos de modernização urbana acelerada em ambientes propícios para a cidade digital (BARBERO, 1996). A troca de informações telemáticas possibilita que as pessoas fiquem liberadas do confinamento espaço-temporal, trânsito e outras dificuldades em locais físicos (CASTELLS, 2005). Não se evidencia a substituição da cidade real pela virtual, o foco está na ampliação do acesso dos cidadãos às atividades de inteligência coletiva e na habitação do ciberespaço, tal como na cidade geográfica, tornando o cidadão por inteiro (LÉVY, 1999).

Cidade digital estratégica pode ser entendida como a aplicação dos recursos da tecnologia da informação na gestão do município e também na disponibilização de informações e de serviços aos munícipes ou cidadãos. É um projeto mais abrangente que apenas oferecer internet para os cidadãos por meio de recursos convencionais de telecomunicações. Vai além de incluir digitalmente os cidadãos na rede mundial de computadores, pois os projetos abrangentes incluem: sistemas de informações para a gestão municipal e para os serviços aos cidadãos; e sistemas de segurança municipal.

\section{Metodologia da pesquisa}

A metodologia de pesquisa empregada se constitui numa abordagem de natureza aplicada numa realidade circunstancial, com ênfase no método indutivo favorecido pelas experiências vivenciadas do autor pesquisador (NACHMIAS; NACHMIAS, 1987; GIL, 1999). Enfatizou um estudo de caso que contemplou uma pesquisa-ação, considerando a 
Prefeitura e suas unidades locais. Mesclou abordagens justificadas pelo ecletismo e integração de métodos indissociáveis (YIN, 1994; VERGARA, 2005).

A elaboração do projeto foi de ago/2009 a jul/2010. A amostra da pesquisa-ação contemplou o Município de Vinhedo-SP, Brasil. A unidade de observação contemplou servidores municipais e cidadãos (trabalhadores, estudantes, aposentados, donas de casa, vereadores, e empresários). O protocolo da pesquisa-ação é parte integrante da metodologia utilizado no projeto que tem como variáveis suas fases e subfases. Vinhedo faz parte da Região Metropolitana de Campinas e tem uma população de 62.240 habitantes. O projeto está em implantação no ano de 2011 e será finalizado em 2012.

\section{Modelo de cidade digital estratégica}

A literatura clássica relaciona a cidade digital com a coleta, estruturação e disponibilização de informações por meios digitais para que os cidadãos possam interagir entre si e com o governo, interligando-os na rede digital de um determinado território. Posteriormente essa rede pode possibilitar a integração de recursos tecnológicos e disponibilizar serviços públicos e respectivas informações em diferentes realidades virtuais ampliadas do espaço urbano e rural. Os referidos serviços municipais podem facilitar a vida dos cidadãos em termos de tempo, espaço e até de qualidade de informações, possibilitando ampliar a participação do cidadão na gestão do município.

O modelo proposto de cidade digital estratégica exigiu para sua implantação a elaboração dos projetos: planejamento estratégico do município (PEM) com os objetivos e estratégias do município por meio das funções ou temáticas municipais; planejamento de informações municipais (PIM); e planejamento da tecnologia da informação (PTI) do município, prefeitura e organizações públicas municipais envolvidas. Os modelos de informações das funções ou temáticas municipais são os principais produtos do projeto PIM que são pré-requisitos para o planejamento dos sistemas de informações (SI) e sistemas de conhecimentos (SC) municipais e respectivos perfis de recursos humanos necessários $(\mathrm{RH})$ sejam dos gestores locais, dos servidores municipais ou dos munícipes ou cidadãos. O projeto PTI possibilitará o planejamento dos recursos da tecnologia da informação (TI) e respectivos serviços municipais oferecidos pelo município aos munícipes ou cidadãos. Essas integrações $(\leftrightarrow \uparrow)$ do modelo proposto e dos respectivos projetos municipais em implantação podem ser observadas na Figura 1.

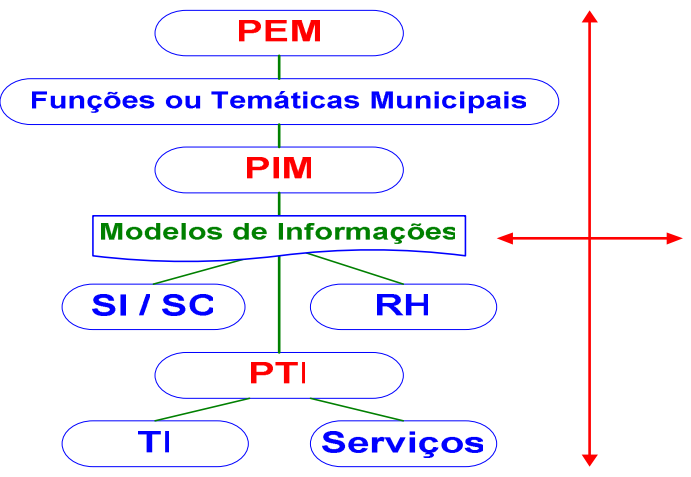

Figura 1. Modelo de Cidade Digital Estratégica. 
O modelo em implantação faz parte de um amplo projeto denominado Planejamento Estratégico da Tecnologia da Informação para Cidade Digital Estratégica. Contemplou a Prefeitura, suas Secretarias Municipais, uma Autarquia e demais unidades municipais, como escolas, postos de saúde, praças sociais de atendimento aos munícipes.

Com a participação dos servidores municipais e dos cidadãos (trabalhadores, estudantes, aposentados, donas de casa, vereadores, empresários entre outros) foram elaboradas 1.331 Listas de Atividades Municipais constando as principais atividades ou processos de tarefas municipais elaboradas. Foram modeladas 18.200 informações operacionais e gerenciais para todo o Município, Prefeitura e respectivas unidades. Tais informações formalizam seus desejos, interesses e principalmente, suas necessidades personalizadas, ou seja, direcionadas para a realidade do município. Além dessas informações, foram planejados e priorizados 140 sistemas de informações municipais propostos.

A partir de licitações estão sendo implantados os SI, os recursos da TI, os serviços e a internet para os munícipes.

\section{Conclusão}

Para o desenvolvimento dos projetos de cidades inteligentes é necessário planejar e disponibilizar informações, sistemas e serviços para seus gestores e cidadãos.

Do ponto de vista da gestão municipal, as informações planejadas podem contribuir na gestão das cidades inteligentes. Ainda, do ponto de vista da participação dos munícipes, também podem propiciar aos cidadãos o exercício da cidadania na medida em que participam do planejamento, estruturação, guarda e disponibilização de informações para seu uso e benefício no que tange ao aumento de sua qualidade de vida.

Indubitavelmente o planejamento estratégico das informações municipais e o respectivo projeto de cidade digital estratégica em implantação, tal como o planejamento estratégico municipal, podem se constituir em inexoráveis instrumentos coletivos e participativos de gestão de prefeituras e de cidades inteligentes.

Apesar das dificuldades e limitações, a os resultados auferidos e a conclusão reiteram a importância das metodologias de planejamentos municipais e do modelo implementado coletivamente pelos servidores municipais, gestores locais e cidadãos, e aceitos como instrumentos para contribuir de forma efetiva na gestão municipal e na implantação de projetos de cidade digital estratégica. Com a implementação desses projetos, poderão ser ampliados o espaço público democrático, a transparência, efetividade e governabilidade dos serviços municipais, o desenvolvimento social, urbano e regional. E como conseqüência, a qualidade de vida dos cidadãos também poderá ser mais adequada.

\section{Referências}

ATKINSON, R. (1997). The digital technology revolution and the future of US cities. Journal of Urban Technology 4(1): 81-98.

BARBERO, J. M. (1996). La ciudad virtual: transformationes de la sensibilidad y nuevos escenarios de comunicaión. Revista de la Universidad del Valle. n. 14, Cali.

BATTEN, D. (1995). Networked cities: creative urban agglomerations for the 21st century. Urban Studies 32(2): 313-327. 
BESSELAAR, P. V. D.; BECKERS, D. (2009). Demographics and sociographics of the digital city. Disponível em: <http://portal.acm.org/citation.cfm?id=701393>. Acesso em: 2 fev. 2009.

CASTELlS, M. (2005). A Sociedade em Rede. A era da Informação: economia, sociedade e cultura. 8 ed. São Paulo: Paz e Terra.

FIRMINO, R. J. (2004). Building the virtual city: the dilemmas of integrative strategies for urban and electronic spaces. Doctoral thesis, University of Newcastle.

GIL, A. C. (1999). Métodos e técnicas de pesquisa social. 5. ed. São Paulo: Atlas.

GUERREIRO, E. P. (2006). Cidade digital: infoinclusão social e tecnologia em rede. São Paulo: SENAC São Paulo.

HENDERSON, J. C.; VENKATRAMAN, N. (1993). Strategic alignment: leveraging information technology for transforming organizations. IBM Systems Journal, v. 32, n. 1, p. $4-16$.

LEDERER, A. L.; MAHANEY, R. C. (1996). Using case tools in strategic information system planning. Information Systems Management Journal, USA, v. 13, n. 4, p.4752, Fall.

LEFEBVRE, H. (1991). The production of space. Oxford: Basil Blackwell.

LEMOS, A. (Org.). (2005). Cibercidades II. Ciberurbe: a cidade na sociedade da informação. Rio de Janeiro: Editora E-Papers.

LÉVY, P. (1999). Cibercultura. São Paulo: Editora 34.

NACHMIAS, D.; NACHMIAS, C. (1987). Research methods in the social sciences. 3th ed. New York: St. Martin's Press.

REZENDE, D. A. (2005). Planejamento de informações públicas municipais: guia para planejar sistemas de informação, informática e governo eletrônico nas prefeituras e municípios. São Paulo: Atlas.

REZENDE, D. A. (2011). Planejamento de sistemas de informação e informática: guia prático para planejar a tecnologia da informação integrada ao planejamento estratégico das organizações. 4 ed. São Paulo: Atlas.

REZENDE, D. A.; CASTOR, B. V. J. (2006). Planejamento estratégico municipal: empreendedorismo participativo nas cidades, Prefeituras e organizações públicas. 2 ed. Rio de Janeiro: Brasport.

SHIODE, N. (2000). Urban planning, information technology, and cyberspace. Journal of Urban Technology 7 (2): 105-126.

TURBAN, E.; McLEAN, E.; WETHERBE, J. (1996). Information technology for management: improving quality and productivity. New York: John Wiley and Sons.

VERGARA, S. C. (2005). Métodos de pesquisa em administração. São Paulo: Atlas.

YIN, R. K. (1994). Case study research: design and methods. London: Sage Publications Inc., USA. 